Document downloaded from:

http://hdl.handle.net/10251/59498

This paper must be cited as:

Broatch Jacobi, JA.; Tormos Martínez, BV.; Olmeda González, PC.; Novella Rosa, R. (2014). Impact of biodiesel fuel on cold starting of automotive direct injection diesel engines. Energy. 73:653-660. doi:10.1016/j.energy.2014.06.062.

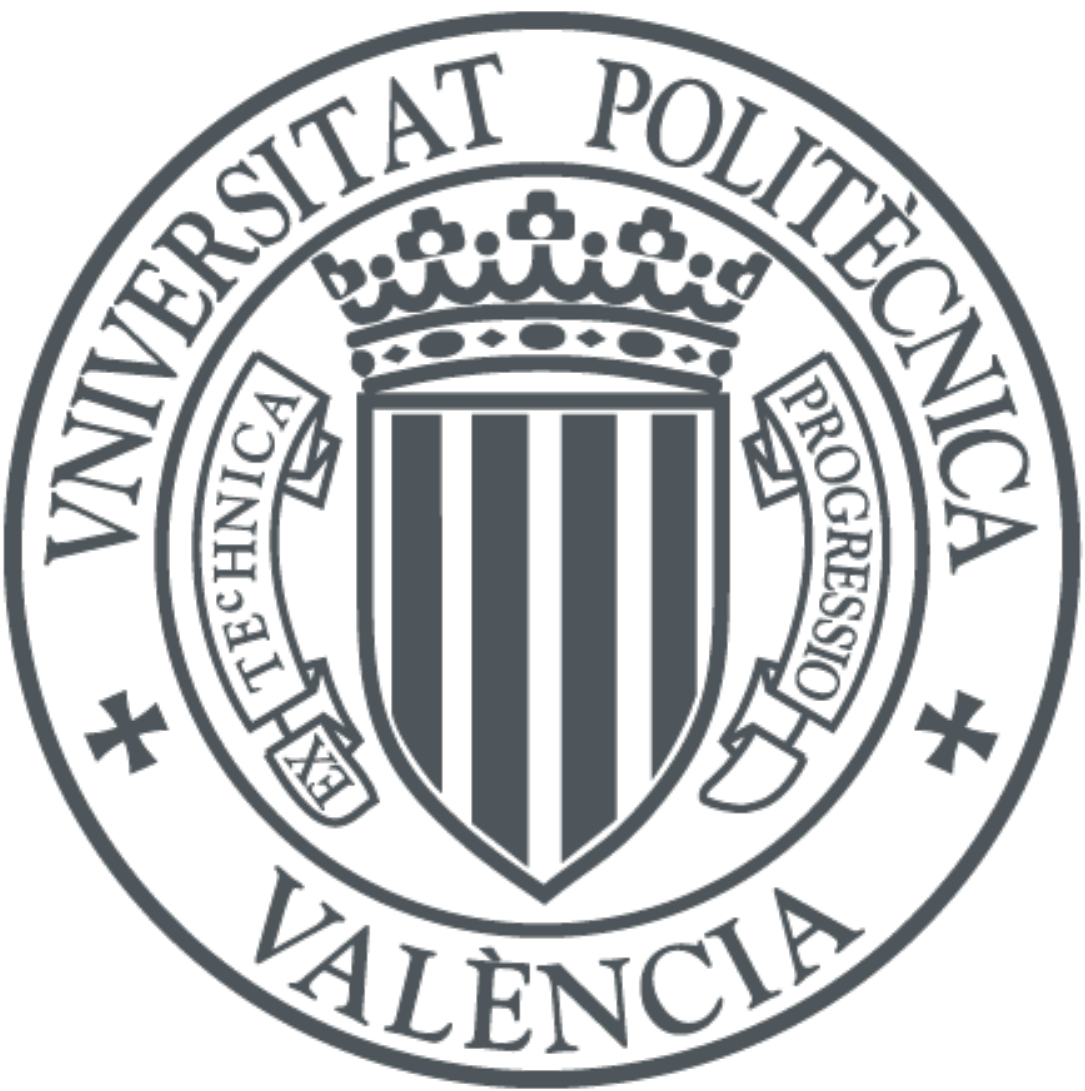

The final publication is available at

http://dx.doi.org/10.1016/j.energy.2014.06.062

Copyright Elsevier

Additional Information 


\title{
Impact of biodiesel fuel on cold starting of automotive DI diesel engines
}

\author{
A. Broatch*, B. Tormos, P. Olmeda, R. Novella \\ CMT-Motores Térmicos, Universitat Politècnica de València, Aptdo. 22012, E-46071 Valencia, Spain.
}

\begin{abstract}
The use of biodiesel fuels in diesel engines is gaining attention as a promising solution to control $\mathrm{CO}_{2}$ emissions. Great research efforts have been carried out to identify the impact of biodiesel physical and chemical properties on engine systems and processes. Most of these investigations were performed in warm conditions, but the suitability of biodiesel for starting the engine at under-zero ambient temperatures has not widely evaluated. The surface tension and the viscosity of biodiesel fuels are higher compared to those of standard diesel and, in cold conditions, these differences become critical since the injection fuel rate is largely affected and consequently the combustion process can be deteriorated. In order to improve its flow characteristics at cold temperatures and make them more suitable for low temperatures operation, additives are used in biodiesel fuels. In this paper the suitability of different biodiesel fuels, with and without additives, for cold starting of DI diesel engines has been evaluated. The results have shown that the engine start-ability with pure biodiesel fuels can be largely deteriorated. However, using diesel/biodiesel blends the start-ability of the engine can be recovered with the additional benefit of reducing the opacity peak of the exhaust gases.
\end{abstract}

Keywords: Biodiesel fuels, diesel engines, cold starting, opacity peak

\section{Nomenclature}

Abbreviations

$B S F C \quad$ Brake Specific Fuel Consumption

$C F P P$ Cold Filter Plugging Point

$\mathrm{CO}$ Carbon Monoxide

$\mathrm{CO}_{2} \quad$ Carbon Dioxide

$D I \quad$ Direct Injection

ECE Economic Commission for Europe

$E C U$ Electronic Control Unit

$E G R \quad$ Exhaust Gas Recirculation

ELR European Load Response

FIS Fuel injection system

ID Ignition Delay

$N O_{x} \quad$ Nitrogen Oxides

$\mathrm{O}_{2} \quad$ Oxygen

$S A E \quad$ Society of Automotive Engineers

$\mathrm{SO}_{2} \quad$ Sulfur Dioxide

UHC Unburned Hydro Carbons

$V G T \quad$ Variable geometry turbocharger
*Corresponding author. Tel.: +34 96 3877650, fax: +3496 3877659 .

Email address: abroatch@mot.upv.es (A. Broatch)

\section{Introduction}

Nowadays, petroleum-based fuels are obtained from limited reserves, and thus the search for other fuel resources is crucial in order to attend the worldwide demand of energy. In particular, biodiesel blends have emerged in the last years as an alternative fuel for transportation. According to the European Commission, even though the current high production cost of the renewable energies, biofuels are now probably the most promising way to reduce the fossil fuel dependence of transport vehicles powered by diesel engines [1].

Bio-fuels, which are obtained from vegetable oil resources, appear to be an excellent substitute for fossil fuel, because their production is simple, they are biodegradable, nontoxic, recyclable, benzene-free and cleaner than fossil fuels $[2,3,4]$. Due to their miscibility with the standard diesel fuel, it can be used either pure or in blends [5]. Additionally, bio-fuels have an excellent lubricity and its use does not require considerable modifications in the engine hardware.

In addition, this alternative fuel allows a significant reduction of pollutant emissions of diesel engines, most notably of carbon dioxide $\left(\mathrm{CO}_{2}\right)$. In comparison with the standard diesel fuel, the use of biodiesel blends can produce reductions of $78 \%$ of net $\mathrm{CO}_{2}$ emissions, due to the carbon neutral cycle of such fuels [6]. In this cycle, the $\mathrm{CO}_{2}$ released into the atmosphere, when the biodiesel fuel burns, is recycled by growing plants, which are later converted into fuel. Since the sulfur and the aromatic content of biodiesel fuels are negligible while their oxygen $\left(\mathrm{O}_{2}\right)$ con- 
centration is substantially high [7], significant reductions of sulfur dioxide $\left(\mathrm{SO}_{2}\right)$, soot, carbon monoxide $(\mathrm{CO})$ and unburned hydrocarbons(UHC) can be achieved [8, 9, 10].

Due to their higher Cetane number, a longer ignition delay (ID) is produced and hence the formation of nitrogen oxides $\left(\mathrm{NO}_{x}\right)$ during combustion is usually increased $[11,12]$. Since the heat value of biofuels is lower than that of standard diesel fuel, the brake specific fuel consumption (BSFC) of diesel engines increases while the thermal efficiency is scarcely affected $[13,14,15]$.

The suitability of bio-fuels for controlling CO and UHC emissions at high idling operating conditions has been also confirmed. In fact, the higher the biodiesel percentage in biodiesel/diesel blends, the lower the $\mathrm{CO}$ and UHC emission levels, while $\mathrm{NO}_{x}$ emissions remain constant or even decrease slightly for biodiesel ratio up to $5 \%$, and tend to increase for ratios above $5 \%$ [16].

The major drawbacks of bio-fuels are associated with their effects on engine operation. Indeed, the use of such a fuel can cause clogging of the fuel lines and injector coking. Moreover, due to the higher surface tension and viscosity of biodiesel fuels, the hydraulic behaviour of the injector can be affected and consequently an adequate atomization before the combustion process is hardly achieved [17]. As a consequence, on one hand carbon deposits can be promoted and the sticking of piston rings can be produced as well $[18,19]$; on the other hand, the lack of atomization has a negative impact on the vaporization process, and consequently on the auto-ignition of the fuel. Since misfiring is frequently produced in those conditions, in particular, this issue is harmful for the start-ability of engines under below-zero ambient temperatures. Under these unfavorable conditions, the increase of the oil viscosity [20] and the decrease of battery performance cause very low cranking speeds and quite high blow-by levels [21, 22] and, additionally, fuel-air mixing is hindered due to the weak air motion [23].

Therefore, while most of the properties of biodiesel are comparable to those of petroleum-based diesel fuel, the major challenge when using biodiesel as an alternative fuel for diesel engines is still the improvement of its low temperature flow characteristics. The biodiesel fuels typically will display higher cloud points and pour points, and this is a great handicap for biodiesel usage [24]. The pour point is the temperature at which a fuel can no longer be poured due to gel formation. Crystallization of the saturated fatty acid methyl ester components of biodiesel at cold ambient temperature causes fuel starvation and operability problems as solidified material clogs fuel lines and filters. With decreasing ambient temperature more solids form and material approaches the pour point. Furthermore, it is well established that the presence of a higher amount of saturated components increases the cloud point and pour point of biodiesel. Potential solutions to this problem include the use of specific additives or blending the given biodiesel with other fuels such as ethanol or kerosene. Specific improvers such as olefin-estercopolymers decrease by $33 \%$ the dynamic viscosity of soybean biodiesel even with very low contents of around $0.03 \%$ [25]. Blending the biodiesel with ethanol or kerosene at ratios up to $20 \%$ [26] also decreases by $30 \%$ the kinematic viscosity, improves the $\mathrm{NO}_{x}$-soot trade-off compared to raw bio-diesel fuel, and promotes the atomization of the fuel, being an interesting option for solving the problem.

In this framework, the objective of this paper focuses on investigating experimentally the suitability of different biodiesel fuels, with and without additives, for keeping the engine start-ability at low temperature conditions similar to that obtained with standard diesel fuel. The most common parameter used to evaluate the cold performance of pure biodiesel or biodiesel blends is the so-called Cold Filter Plugging Point (CFPP), as observed in the European standard [27]. The Cold Filter Plugging Point is the temperature at which a fuel jams the filter due to the formation of agglomerates of crystals [28]. Additional fuel characteristics could be used for evaluating the effects on cold starting, such as viscosity, cetane number, ignition quality and many others, but considering that the CFPP is the unique parameter limited in the European standard, the study presented in this paper considers mainly this parameter and includes a detailed analysis about its feasibility to characterize the suitability of biodiesel fuels for cold starting of diesel engines.

This paper is organized into four main sections. First, a description of the experimental facilities used in the study is presented. In section 4 , the methodology used is detailed, whereas the parameters considered in order to characterize the start-ability of the engine are defined in section 4. Following, in section 5 the results obtained for the different fuels tested are discussed in detail. Finally, the conclusions extracted from this work are summarized.

\section{Experimental configuration}

\subsection{Evaluated engine}

The experiments were performed on a light-duty 4cylinder Euro V turbocharged DI diesel engine, with a total displacement of $1.5 \mathrm{l}$ and FIS with common rail. The engine coupled to the gear box was mounted on a test bench, so that the contribution of the gear box to the total load that the engine must overcome during the starting can be also considered in the tests. The specifications of both engine and FIS are summarized in Table 1.

\subsection{Engine test rig}

Cold starting tests have been performed in a climatic chamber where it is possible to control the ambient temperature from -30 up to $15^{\circ} \mathrm{C}$. Figure 1 shows a diagram of the climatic chamber used. The humidity in the main chamber was controlled by a pre-chamber, which supplied cold dry air through depression wall valves. The engine bench was located in the main chamber. The fuel tank and the battery were also placed in the main chamber, so 
Table 1: Engine specifications.

\begin{tabular}{lcc}
\hline $\begin{array}{l}\text { Engine Type } \\
\text { Fuel Injection }\end{array}$ & $\begin{array}{c}\text { Direct-injection diesel engine } \\
\text { Common Rail }\end{array}$ \\
$\begin{array}{l}\text { Turbocharger } \\
\text { Cylinders }\end{array}$ & $\begin{array}{c}\text { Variable Geometry Turbine } \\
\text { Swept volume }\end{array}$ & 4 in line \\
Bore & $\left(\mathrm{dm}^{3}\right)$ & 1.5 \\
Stroke & $(\mathrm{mm})$ & 75 \\
Compression ratio & $(\mathrm{mm})$ & 80.5 \\
Max. power & $(\mathrm{kW})$ & $65(6: 1$ \\
Max. torque & $(\mathrm{Nm})$ & $200(@ 1900 \mathrm{rpm})$ \\
\hline
\end{tabular}

that both fuel and electrolyte temperatures were similar to those of the rest of fluids before the test began.

The soaking time required for maintaining stable temperatures in the engine fluids (oil, coolant, fuel and battery electrolyte) before tests depended on the set-up temperature level: it was about 8 hours for tests at $-10^{\circ} \mathrm{C}$. The temperature of these fluids was measured by means of Class 1 Platinum thermo-resistances.

In addition to the fluids temperature, the temporal evolution of different parameters relevant for the study was also measured during engine starting. Figure 1 also shows a sketch of the instrumentation used to measure the parameters which characterize the engine starting.

The instantaneous intake air and exhaust gas temperatures were measured using $\mathrm{K}$ type thermocouples. With this aim, a $0.5 \mathrm{~mm}$ diameter bare wire thermocouple was placed in each intake port, while a $1 \mathrm{~mm}$ diameter protected thermocouple was placed in the exhaust manifold.

Instantaneous intake air mass flow rate and blow-by were measured by means of a hot film anemometer placed downstream of the air filter and the 442 AVL blow-by meter, respectively. The exhaust gas opacity was measured continuously with the AVL 439 partial flow opacimeter, which is particularly suitable for dynamic testing measurements with a response time lower than $0.1 \mathrm{~s}$ and an accuracy of $0.1 \%$.

All signals were simultaneously recorded at a constant sampling frequency of $50 \mathrm{kHz}$ with a multi-channel 16bit data acquisition system. To measure continuously the parameters during all the phases characteristic of engine starting -cranking, starting and idling- a base time of 15 $\mathrm{s}$ was chosen for the acquisition. With the purpose of synchronizing the measured variables with the crank angle, the synchronization signal supplied by an optical encoder coupled to the crankshaft was also measured during the tests. An angular resolution of 1 crank angle degree (c.a.d.) was used. With this signal the instantaneous engine speed during starting was also determined.

The accuracy of the instrumentation used is summarized in Table 2

\section{Methodology}

In order to evaluate the impact of biodiesel fuel on the start-ability of the engine at cold ambient temperatures, several blends of three different types of biodiesel were considered. With this aim, at any set-point ambient temperature, tests were performed with the baseline engine settings, so that it is ensured that any variation of the starting performance was caused by the fuel itself and not by differences in other settings.

With the purpose to define suitable reference conditions, preliminary tests with standard diesel fuel and with the baseline engine settings were performed. From these tests, the reference values of the parameters defined in Section 4 were obtained for each of the ambient conditions considered in the study. These reference values were compared with those measured with the biodiesel fuels.

Three different types of biodiesel from different origin and importance on the Spanish market have been used in the tests. One of them, labelled biodiesel C, was a raw biodiesel derived from used cooking oils. Biodiesel D, was a biodiesel $\mathrm{C}$ with additives in order to improve its cold flow characteristics and therefore its CFPP is reduced. Finally, the third fuel, biodiesel E, was a rapeseed oil with cold flow improver. Table 3 shows a summary of the main properties of the fuels used. The data from biodiesel fuels have been provided by fuel manufacturers, but the data associated with the cold flow improver were not been facilitated.

In order to consider in the study fuels that can be purchased in the market, additionally to pure biodiesel, two blends of biodiesel $\mathrm{C}$ and $\mathrm{D}$ with standard diesel fuel in volume concentrations of $30 \%$ and $50 \%$ were also tested. Furthermore, with the purpose of considering the average climatic conditions expected in Spain, cold starting tests at ambient temperatures of $0,-5$ and $-10^{\circ} \mathrm{C}$ were performed. In summary, Table 4 shows the tests matrix considered in this investigation.

In order to avoid any effect from the fuel used in the previous test, after each test the fuel line was emptied, the main tank was refilled with a different fuel, and then the engine was run at high speed until the oil temperature reach $80^{\circ} \mathrm{C}$ before any new measurements were taken. 


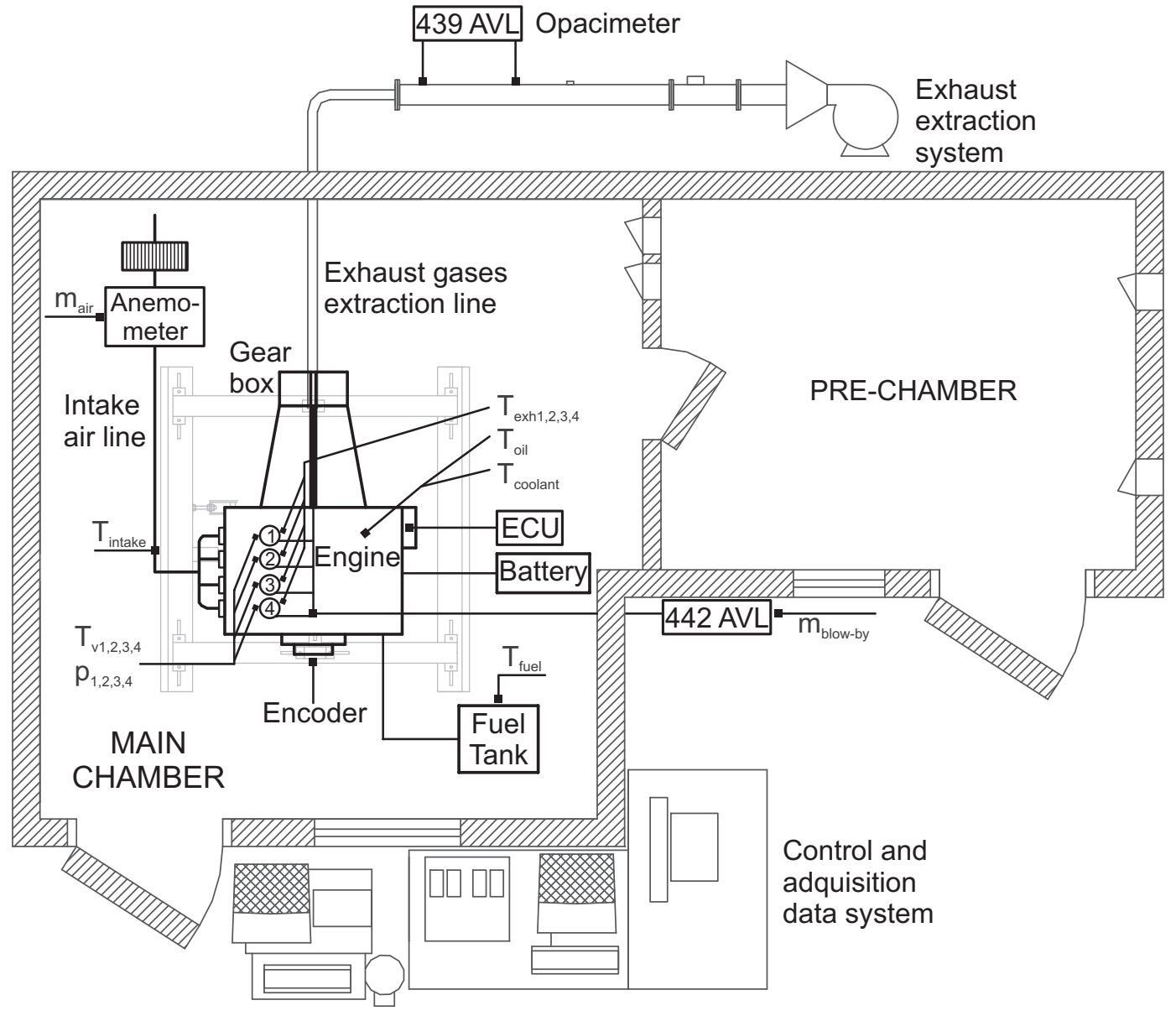

Figure 1: General layout of the test facility used in the study.

Table 2: Accuracy of the instrumentation used.

\begin{tabular}{lll}
\hline Sensor & Variable & Accuracy [\%] \\
\hline Thermocouples & Instantaneous temperatures & 0.35 \\
Thermoresistances & Fluids temperatures & 0.04 \\
Encoder & Engine speed & 0.006 \\
Air mass flow meter & Air mass & 0.12 \\
Blow-by meter & Blow-by & 1.0 \\
Opacimeter & Opacity & 0.1 \\
Piezoresistive & Pressure drop in the fuel filter & 0.65 \\
\hline
\end{tabular}

Table 3: Characteristics of the fuels tested.

\begin{tabular}{lcccc}
\hline Fuel & diesel & Biodiesel C & Biodiesel D & Biodiesel E \\
\hline CFPP $\left({ }^{\circ} \mathrm{C}\right)$ & -7 & -3 & -8 & -20 \\
Density at $15^{\circ} \mathrm{C}\left(\mathrm{kg} \mathrm{m}^{-3}\right)$ & 843 & 881.4 & 881.7 & 883.9 \\
Viscosity at $40^{\circ} \mathrm{C}\left(\mathrm{mm}^{2} \mathrm{~s}^{-1}\right)$ & 2.847 & 4.173 & 4.314 & 4.581 \\
Ester content $(\% \mathrm{~m} / \mathrm{m})$ & - & 99.3 & 96.8 & 97.3 \\
Cetane number & 51.52 & 56.5 & $>51$ & $>51$ \\
Water content $(\mathrm{ppm})$ & 92 & 352 & 407 & 297 \\
Flash Point $\left({ }^{\circ} \mathrm{C}\right)$ & 66.5 & 165 & 162 & 180 \\
\hline
\end{tabular}


In addition, a preconditioning procedure was followed between each fuel change in order to remove particulate matter potentially deposited on the exhaust pipe walls, which could be blown out and released during the following starting tests, thus leading to faulty measurements of smoke opacity and erroneous interpretations for each fuel blend and its effects on smoke emission.

Table 4: Test matrix considered in the study.

\begin{tabular}{lcc}
\hline $\begin{array}{l}\text { Fuel } \\
\text { (base) }\end{array}$ & $\begin{array}{c}\text { Temp. } \\
\left({ }^{\circ} \mathrm{C}\right)\end{array}$ & $\begin{array}{c}\text { Biodiesel } \\
\text { Blending }(\%)\end{array}$ \\
\hline Standard diesel & $0,-5,-10$ & 0 baseline \\
Biodiesel C & $0,-5$ & $30,50,100$ \\
Biodiesel D & $-5,-10$ & $30,50,100$ \\
Biodiesel E & -10 & 100 \\
\hline
\end{tabular}

\section{Engine start-ability parameters}

According to Broatch et al. [23], the starting performance of the engine has been evaluated by means of three parameters: the starting time, the speed stability after starting and the opacity peak of exhaust gases. Figure 2 shows a plot of the engine speed evolution and the instantaneous opacity measured during the starting of the engine, where these parameters are also indicated. In order to evaluate the capacity of the fuel to flow through the FIS without plugging such a system, the pressure drop across the fuel filter during the starting was also measured and analyzed.

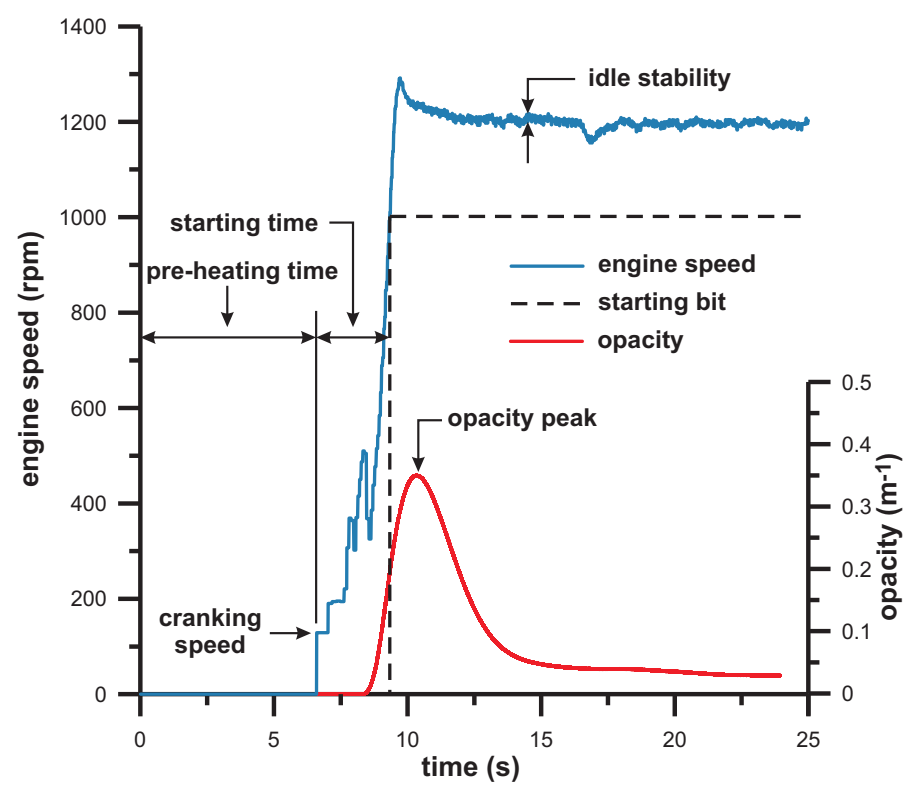

Figure 2: Characteristic variables for the evaluation of the cold startability of the engine.

\subsection{Starting time}

The starting time is the time between the instant when the cranking phase begins (the starter is switched on) and the instant when the engine overcome a given threshold speed which depends on the ambient temperature and, that controls the state of the engine by means of a starting bit. The starting time is preceded by the pre-heating time, which is the time required by the glow plugs to achieve the maximum tip temperature, so that the autoignition of the fuel is provoked. This time depends solely on the ambient temperature. In addition, since the injection of the fuel begins when the fuel pressure available in the rail reaches a minimum value, the starting time is frequently split in cranking and acceleration times. The cranking time is the period of time between the instant when the starter is switched on and the instant when the first combustion is promoted. The acceleration time begins when this first combustion is produced and finished when the starting bit is activated.

\subsection{Speed stability after starting}

This parameter evaluates both the stability of the combustion process in each one of the cylinders and the dispersion of the combustion between the cylinders. The engine speed stability can be calculated by determining the standard deviation of either the instantaneous speed or the cycle-to-cycle imep. This parameter was determined here by calculating the standard deviation of the engine speed during $60 \mathrm{~s}$ after the overshoot was attenuated.

\subsection{Opacity Peak}

The instantaneous opacity is measured during the cold starting of Diesel engines in order to evaluate qualitatively the plume of smoke emitted at the exhaust. The opacity peak is usually accepted as a metric for quantifying the intensity of such a plume.

\subsection{Pressure drop across the fuel filter}

In order to quantify the capacity of the fuel to maintain its fluidity at the temperatures defined in the study, so that the FIS is not plugged during the starting of the engine, the pressure drop across the fuel filter was instantaneously measured by means of a differential pressure transmitter during the engine starting. The maximum pressure difference measured was considered as an indicator of the turbidity of the fuel mainly caused by the crystallization of the paraffins at cold temperatures.

\section{Results and discussion}

This section describes the performance of the engine during the cold starting at low ambient temperatures, using the different biodiesel blends under investigation. In order to evaluate the effect of the biodiesel fuel on the engine startability, the values of the parameters defined in 
Section 4 obtained when the engine starts with the different biodiesel blends are compared with those parameters that qualify the engine starting with the standard diesel fuel.

\subsection{Effect on the starting time}

Figure 3 shows engine starting time operating with the fuels investigated at ambient temperatures ranging between $0{ }^{\circ} \mathrm{C}$ and $-10{ }^{\circ} \mathrm{C}$.

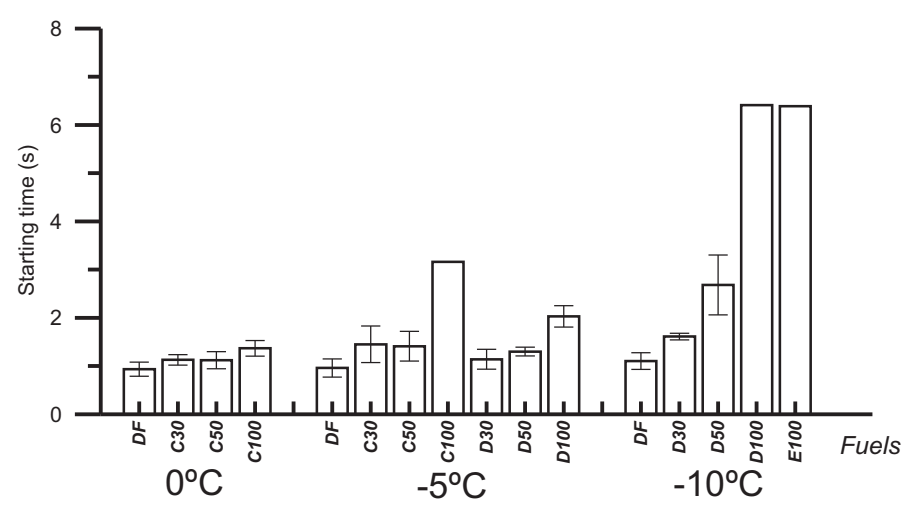

Figure 3: Effect of biodiesel blends on the starting time of the engine at low temperatures.

In general, for all temperatures the engine starting time progressively increases by increasing the biodiesel content in the fuel, while at each temperature the longer times are obtained for pure biodiesel fuels C100, D100 and E100. In fact, the results show that with diesel fuel the starting time is almost the same independently from the ambient temperature, but the starting time is much more sensitive to the ambient temperature when the engine operates with biodiesel blends and in particular with pure biodiesel fuels. Then, pure biodiesel fuels are not suitable for keeping the starting time at reasonable levels in cold conditions, with ambient temperatures below $0{ }^{\circ} \mathrm{C}$.

At $0{ }^{\circ} \mathrm{C}$, the differences obtained comparing diesel fuel with C30 and C50 blends are in the range of the dispersion observed in the tests and therefore negligible. In addition, since the difference observed with pure biodiesel C100 is not so apparent as would be expected, one can conclude that at this ambient temperature the impact of biodiesel fuel on the starting time is also negligible.

The results obtained with biodiesel $\mathrm{C}$ and $\mathrm{D}$ at $-5{ }^{\circ} \mathrm{C}$ indicate that CFPP of the fuel should be undoubtedly considered, but it is not the determinant parameter to evaluate the suitability of a fuel for promoting adequate combustion during the starting of modern diesel engines at cold ambient conditions. The difference of the starting times obtained with diesel fuel and pure biodiesel D100, whose CFPP temperatures are similar, evidences that apart of the effect that the fuel clouding could have on the operation of the FIS, there are another parameter characteristic of the fuel that might affect negatively to the combustion during the acceleration phase of the engine. Observing the characteristics of these fuels presented in Table 3, it is easy to identify that from the parameters that can impact to combustion, the viscosity is the parameter with the highest variation. Indeed, the viscosity of the biodiesel at 40 ${ }^{\circ} \mathrm{C}$ is 1,5 times higher than that of the diesel fuel. The viscosity of the fuel affects to the needle lift of the injector and therefore, to the injected mass fuel rate. However, the higher clouding of pure biodiesel $\mathrm{C} 100\left(\mathrm{CFPP}=-3{ }^{\circ} \mathrm{C}\right)$ might be the reason why the engine took longer time to start than with D100 $\left(\mathrm{CFPP}=-8{ }^{\circ} \mathrm{C}\right)$.

The positive effect of the reduction of the fuel viscosity on the starting time at $-5{ }^{\circ} \mathrm{C}$ is clearly noticed analyzing the results obtained with biodiesel blends C30, C50, D30 and D50. In all cases, due to the action of the lower viscosity of the diesel fuel, the starting times are shorter than those obtained with the pure biodiesel fuels.

Results at $-10^{\circ} \mathrm{C}$ are qualitatively similar than those obtained at $-5^{\circ} \mathrm{C}$, so previous discussion is still valid at this lower ambient temperature. In this case, the difference observed between diesel and D30 fuels is not negligible, while the starting time for D50 fuel is more than twice the observed with the diesel fuel. The longer time required by the engine for starting with pure biodiesel fuels D100 and E100, even having lower CFPP than diesel fuel, confirm that the effects associated with the clouding of the fuel -characterized by the CFPP- can be masked by the great impact of fuel viscosity to the rate of injected mass flow and in consequence, to the combustion process.

All tests discussed here were performed keeping the baseline values for both pre-heating and injection settings, and they were defined to optimize the cold start-ability of the engine operating with standard diesel fuel and not with biodiesel blends or pure biodiesel fuels. Since the objective of this investigation focuses on the analysis of the impact of biodiesel fuels on the cold starting of production diesel engines, the fine optimization is out of the scope of this research work. However, the starting times operating with biodiesel fuels are expected to be improved by optimizing those settings for each fuel type.

\subsection{Effect on speed stability after starting}

Figure 4 shows the speed stability after starting of the engine at the conditions described in the previous section. These results indicate that in tests with standard diesel fuel, the speed stability after starting deteriorates as the ambient temperature is colder. However, this trend is not observed when biodiesel blends are employed.

Indeed, the speed stability at $0{ }^{\circ} \mathrm{C}$ is deteriorated as the content of biodiesel $\mathrm{C}$ in the blend is increased. However, at $-5{ }^{\circ} \mathrm{C}$ the results for this biodiesel show the opposite trend. At this temperature, the speed stability obtained with biodiesel $\mathrm{D}$ deteriorates in proportion to the concentration of biodiesel in the blend, but the opposite behaviour was obtained at $-10{ }^{\circ} \mathrm{C}$ with the same fuel.

Variation in speed stability can be related to a variation in starting period considering that these two parameters 


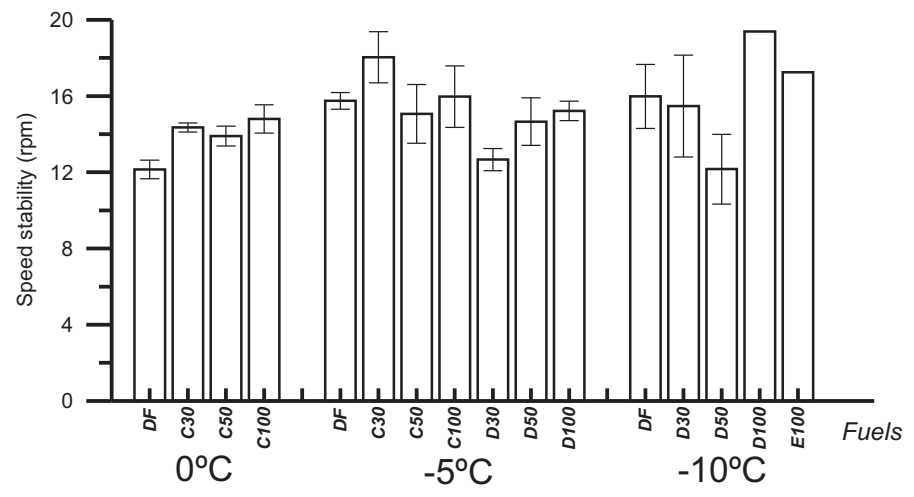

Figure 4: Effect of biodiesel blends on the speed stability after starting of the engine at low ambient temperatures.

are usually interconnected. A longer starting period is very often associated with engine speed stability difficulties due to combustion failures or fuel pump failures.

\subsection{Effect on opacity peak}

The effect of biodiesel blends on the opacity peak of the exhaust gases during the starting of the engine at the ambient temperatures considered in the study is represented in Figure 5.

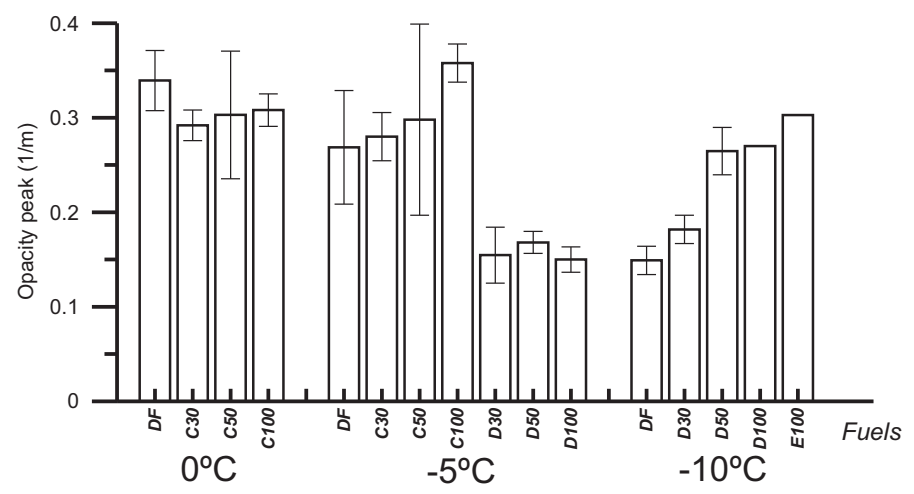

Figure 5: Effect of biodiesel blends on the opacity peak of exhaust gases during the starting of the engine at low ambient temperatures.

This figure shows that the opacity peak is apparently lower as the ambient temperature decreases when the engine starts with standard diesel fuel. However, this trend is not so clear when biodiesel blends are used. With biodiesel $\mathrm{C}$ blends the opacity peak is scarcely reduced as the ambient temperature drops from $0{ }^{\circ} \mathrm{C}$ to $-5{ }^{\circ} \mathrm{C}$, but the opposite was observed during the starting with biodiesel $\mathrm{D}$ blends at $-5{ }^{\circ} \mathrm{C}$ and $-10{ }^{\circ} \mathrm{C}$.

In comparison with standard diesel fuel, the results show that the opacity peak emitted with biodiesel blends is lower whenever the ambient temperature is higher than the CFFP of the blend. In fact, the opacity peaks measured when the engine started at $0{ }^{\circ} \mathrm{C}$ with biodiesel $\mathrm{C}$ blends are lower than the peak measured with standard diesel fuel. These results can be due to the higher oxygen content of biodiesel that should promote a better oxidation of the soot formed during combustion. However, at $-5{ }^{\circ} \mathrm{C}$ -which is a lower temperature than the CFFP of biodiesel $\mathrm{C}$ - the opacity peak is higher than that obtained for standard diesel. At this temperature, the effect remarked before regarding the high oxygen content of biodiesel blends seems to be masked by the effect of the CFFP on the fuel atomization.

On the other side, the results also shown that the scatter between the opacity peaks is bigger as the biodiesel content in the blend is higher.

Finally, the same comments given before regarding the opacity peak emitted with biodiesel $\mathrm{C}$ can be also remarked for the opacity peak measured with biodiesel $\mathrm{D}$ blends at $-5{ }^{\circ} \mathrm{C}$ and $-10{ }^{\circ} \mathrm{C}$.

\subsection{Effect on the pressure drop across the fuel filter}

Figure 6 shows the pressure drop across the filter produced by the considered fuel mixtures at the investigated ambient temperatures.

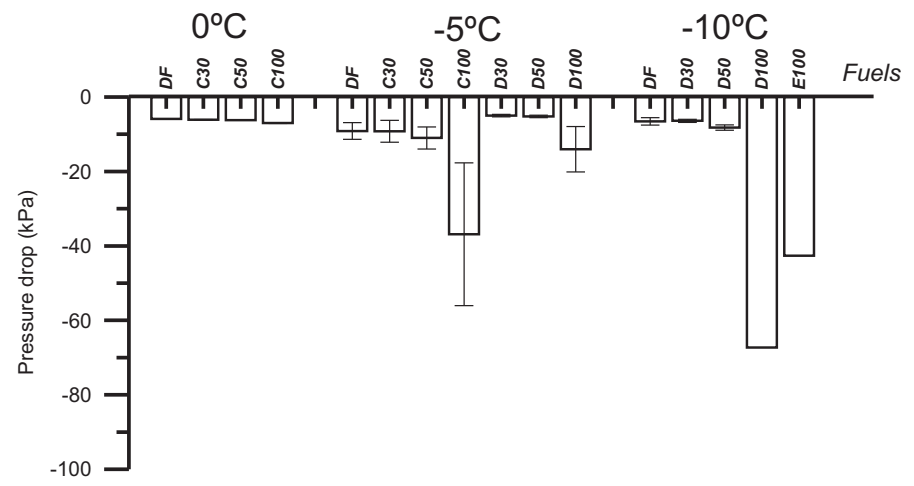

Figure 6: Effect of biediesel blends on the pressure drop across de fuel line during the starting of the engine at low ambient temperatures.

At $0^{\circ} \mathrm{C}$, variations of the pressure drop are negligible between all fuels tested, including the conventional diesel fuel. This result is explained considering that the temperature of $0^{\circ} \mathrm{C}$ is over the corresponding $\mathrm{CFPP}$ for each fuel. However, pressure drop slightly increases from diesel fuel(left) to C100 (right) according to the progressive increment in CFPP of blends as shown in Table 3.

The results for $-5{ }^{\circ} \mathrm{C}$ show that the use of biodiesel C100 increases the pressure drop across the filter compared to the rest of fuels due to its higher CFPP $\left(-3^{\circ} \mathrm{C}\right)$. In this fuel, the massive formation of crystal agglomerates resulted in a clogging effect on fuel filter (as usual using hydrocarbon fuels at extremely low temperatures). This increases the pressure drop up to values of 0.4 bar as a straight consequence of operating the engine at temperatures below the CFPP of this fuel. In addition, the pressure drop measured with this C100 fuel showed a much higher dispersion during the engine cold starting compared to the other fuels tested. However, C30 and C50 blends 
present very similar results, which are comparable to that obtained using conventional diesel fuel. Regarding to the results obtained with biodiesel D, D30 and D50 blends decrease significantly the pressure drop across the fuel filter even comparing with diesel fuel, while the pressure drop measured with D100 is higher than that obtained with diesel fuel despite both fuels have similar values of CFPP. It is clear that this behaviour is due to the effect of the viscosity on the pressure drop.

Analyzing the results obtained at $-10^{\circ} \mathrm{C}$, in comparison with conventional diesel fuel, the pressure drop measured for D30 and D50 blends is negligible. However, as was observed for $-5^{\circ} \mathrm{C}$, pure biodiesel D100 sharply increases the pressure drop across the fuel filter. In this case, since the ambient temperature is lower than the CFPP of the fuel, the pressure drop reaches even higher levels. In regard to E100 fuel, even though it was elaborated in order to have a CFPP of $-20^{\circ} \mathrm{C}$, the pressure drop produced by this fuel is higher than the other fuels with higher CFPP. As was remarked previously for the results of D100 at -5 ${ }^{\circ} \mathrm{C}$, in this case the high pressure drop is caused again by the high viscosity of the fuel.

According to the previous discussion, one can conclude that from the two characteristics of the fuel that have impact on the pressure drop across the fuel filter, the fuel clouding -characterized by the CFPP- and the viscosity, this last characteristic is that of the higher importance. The increment in fuel filter pressure drop caused by the higher viscosity of pure biodiesel fuels, compromises the applicability of this fuels at cold ambient temperatures. However, blending diesel with biodiesel is an interesting alternative to reduce the viscosity of the fuel and therefore, the critical problems related to the clogging of the fuel filter associated with pure biodiesel fuels can be surpassed.

\section{Summary and Conclusions}

An experimental investigation was performed in a 4cylinder HSDI diesel engine operating with conventional diesel, pure biodiesel fuels and also different diesel/biodiesel blends with the aim of evaluating the suitability of these fuels for starting these type of engines at low temperature conditions. The impact of the cold filter plugging point (CFPP) of the fuel on the engine start-ability at cold ambient conditions was also analyzed in detail.

The most relevant conclusions extracted from this research are:

- Independently of the additives used for improving the CFPP of the biodiesel fuels considered, the startability of Diesel engines at under-zero ambient temperatures is deteriorated when pure biodiesel is used. The results obtained at different temperatures below zero have shown that this behaviour is caused principally by the great impact that the higher viscosity of these fuels has on the injection mass flow rate and consequently, on the combustion process.

- In comparison with pure biodiesel, the start-ability of the engine can be apparently improved with diesel/biodiese blends principally due to the significant reduction of the viscosity of this type of fuel. Depending on the percentage of biodiesel in the blend and its CFPP temperature, the starting time at moderate cold temperatures can be comparable with that obtained with diesel fuel, while the peak opacity is reduced.

- The pressure drop across the filter caused by the fuel is much more dependent on the viscosity of the fuel than on its CFPP temperature. Therefore, the use of biodiesel blends instead of pure biodiesel is a suitable solution in order to keep the pressure loss at admissible levels and hence to surpass the limitation of pure biodiesel fuels for starting Diesel engines.

Finally, as a synthesis of this research, it can be remarked that considering the climate conditions expected in Spain along the year, biodiesel blend D50 is the most convenient fuel for the Spanish market. Apart that the production costs of this biodiesel are not so high and its CFPP is similar to that of the standard diesel commercialized in Spain, with this blend the start-ability of Diesel engines is quite similar to that provided by the diesel fuel.

\section{References}

[1] EEC. Communication from the commission to the European council and the European: An energy policy for Europe. Official Journal of the European Communities, 2007.

[2] Anand K, Sharma R, Mehta P. Experimental investigations on combustion, performance and emissions characteristics of neat karanji biodiesel and its methanol blend in a diesel engine. Biomass Bioenerg 2011; 35:533-41.

[3] Saravanan N, Nagarajan G, Puhan S. Experimental investigation on a DI diesel engine fuelled with madhuca indica ester and diesel blend. Biomass Bioenerg 2010;34:838-43.

[4] Tormos B, Novella R, García A, Gargar K. Comprehensive study of biodiesel fuel for HSDI engines in conventional and low temperature combustion conditions. Renew Energy 2010;35:368-78.

[5] Bunce M, Snyder D, Adi G, Hall C, Koehler J, Davila B, Kumar S, Garimella P, Stanton D, Shaver G. Stock and Optimized Performance and Emissions with 5 and $20 \%$ Soy Biodiesel Blends in a Modern Common Rail Turbo-diesel Engine. Energy Fuels 2010;24:928-39.

[6] Senatore A, Cardone M, Buono D, Rocco V. Combustion study of a common rail diesel engine optimized to be fueled with biodiesel. Energy Fuels 2008;22:1405-10.

[7] Muncrief RL, Rooks CW, Cruz M, Harold MP. Combining biodiesel and exhaust gas recirculation for reduction in NOx and particulate emissions. Energy Fuels 2008;22:1285-96.

[8] Thompson GJ, Nuszkowski J. Neat fuel influence on biodiesel blend emissions. Int J Engine Res 2010;11:61-77.

[9] Mrad N, Varuvel EG, Tazerout M, Aloui F. Effects of biofuel from fish oil industrial residue - Diesel blends in diesel engine. Energy 2012;44:955-63.

[10] Vallinayagam R, Vedharaj S, Yang WM, Lee PS, Chua, KJE, Chou, SK. Combustion performance and emission characteristics study of pine oil in a diesel engine. Energy 2013;57:344-51. 
[11] Bermúdez V, Luján JM, Plá B, Linares WG. Comparative study of regulated and unregulated gaseous emissions during NEDC in a light-duty diesel engine fuelled with Fischer Tropsch and biodiesel fuels. Biomass Bioenerg 2011;35:789-98.

[12] Torregrosa AJ, Broatch A, Plá B, Mónico LF. Impact of Fischer Tropsch and biodiesel fuels on trade-offs between pollutant emissions and combustion noise in diesel engines. Biomass Bioenerg 2013;52:22-33.

[13] Luján JM, Tormos B, Salvador FJ, Gargar K. Comparative analysis of a DI diesel engine fuelled with biodiesel blends during the European MVEG-A cycle: Preliminary study (I). Biomass Bioenerg 2009;33:941-7.

[14] Luján JM, Bermúdez V, Tormos B, Plá B. Comparative analysis of a DI diesel engine fuelled with biodiesel blends during the European MVEG-A cycle: Performance and emissions (II). Biomass Bioenerg 2009;33:948-56.

[15] Muralidharan K, Vasudevan D, Sheeba KN. Performance, emission and combustion characteristics of biodiesel fuelled variable compression ratio engine. Energy 2011;36: 5385-93

[16] Rahman SMA, Masjuki HH, Kalam MA, Abedin MJ, Sanjid A, Sajjad H. Production of palm and Calophyllum inophyllum based biodiesel and investigation of blend performance and exhaust emission in an unmodified diesel engine at high idling conditions. Energy Conv Manag 2013;76:362-7.

[17] Salvador FJ, Gimeno J, De la Morena J, Carreres M. Using one-dimensional modeling to analyze the influence of the use of biodiesels on the dynamic behavious of solenoid-operated injectors in common rail systems: Results of the simulations and discussion. Energy Conv Manag 2012;54:122-32.

[18] Gumus M, Kasifoglu S. Performance and emission evaluation of a compression ignition engine using a biodiesel (apricot seed kernel oil methyl ester) and its blends with diesel fuel. Biomass Bioenerg 2010;34:134-9.

[19] Monyem A, Gerpen JHV. The effect of biodiesel oxidation on engine performance and emissions. Biomass Bioenerg 2001;20:31725 .

[20] Buck W, Lohuis J. Lubricant effects on low-temperature diesel engine starting. SAE paper 940097; 1994.

[21] Gonzalez M, Borman G, Reitz R. Study of diesel cold starting using both cycle analysis and multidimensional calculations. SAE paper 910180; 1991.

[22] Cheng K, Shayler P, Murphy M. The influence of blow-by on indicated work output from a diesel engine under cold start conditions. Proc Inst Mech Eng Part D J Automob Eng 2004;218:333-40.

[23] Broatch A, Ruiz S, Margot X, Gil A. Methodology to estimate the threshold in-cylinder temperature for self-ignition of fuel during cold start of diesel engines. Energy 2010;35:2251-60.

[24] Lapuerta M, Armas O, Rodríguez-Fernández J. Effect of biodiesel fuels on diesel engine emissions. Prog Energy Combust Sci 2008;34:198-223.

[25] Boshui C, Yuqiu S, Jianhua F, Jiu W, Jiang W. Effect of cold flow improvers on flow properties of soybean biodiesel. Biomass Bioenerg 2010;34:1309-13.

[26] Bhale PV, Desphande NV, Thombre SB. Improving the low temperature properties of biodiesel fuel. Renew Energy 2009;34:794-800.

[27] EN 14214. Liquid petroleum products - fatty acid methyl esters (fame) for use in diesel engines and heating applications requirements and test methods, 2010.

[28] Payri F, Bermúdez V, Tormos B, Linares WG. Hydrocarbon emissions speciation in diesel and biodiesel exhausts. Atmos Environ $2009 ; 43: 1273-9$. 